INTERNATIONAL JOURNAL
OHARMACEUTICAL SCIENCES
PESEARCH
RESED

Received on 21 April, 2017; received in revised form, 06 July, 2017; accepted, 25 July, 2017; published 01 January, 2018

\title{
SCHIFF BASES DERIVED FROM 2-HYDROXY AND 2- METHOXY NAPHTHALDEHYDE: EXPLORATION OF IN SILICO DOCKING, DNA CLEAVAGE, ANTIBACTERIAL ACTIVITIES AND SAR
}

R. Devika Bhai ${ }^{1}$, C. R. Girija ${ }^{* 1,2,3}$ and K. Ramakrishna Reddy ${ }^{3}$

Research and Development Centre ${ }^{1}$, Bharathiar University, Coimbatore - 641046, Tamil Nadu, India. SSMRV Degree College ${ }^{2}$, Jayanagar $4^{\text {th }} \mathrm{T}$ - block, Bangalore - 560041, Karnataka, India.

Department of P. G. Studies and research in Chemistry ${ }^{3}$, Government Science College, Nrupathunga Road, Bangalore - 560001, Karnataka, India.

Keywords:

Schiff Base, Antibacterial properties,

Docking Studies, Knowledge - based interactions, DNA cleavage

\section{Correspondence to Author:}

Dr. C. R. Girija

Associate Professor,

Department of P. G. Studies and research in Chemistry, Government

Science College, Nrupathunga Road,

Bangalore - 560001, Karnataka,

India.

E-mail: girija.shivakumar@rediffmail.com

\begin{abstract}
Antibacterial activities, molecular docking and DNA cleavage activities of five structurally related Schiff bases [L3 (a), L3 (b), L3 (c) L3 (d) and L3 (e)] were performed and their structure activity relationship was studied. Antibacterial activities of these compounds against gram-negative and gram-positive bacteria were evaluated by using well diffusion method and the compound L3 (c); 1-[(E)-(4hydroxyphenyl) iminomethyl] naphthalene-2-ol which carries two hydroxyl functional groups was observed as one of the most dynamic antibacterial agents. Docking interactions against p55blk kinase protein were investigated. The compound L3 (a); 1-[(E)-(3-nitrophenyl)iminomethyl]naphthalene-2-ol exhibited good docking proficiency with 24 interactions based on statistical potentials and the compound L3 (d); (E)1-(2-methoxy-1-naphthyl)- N- (3-nitro phenyl) methanimine showed significant docking interaction based on hydrogen bonding. DNA cleavage efficiency of all the Schiff bases was investigated using Lambda DNA by gel electrophoresis method.
\end{abstract}

INTRODUCTION: The search for new antibacterial agents against pathogenic microorganisms those developed resistance to the existing antibiotic drugs has become an essential area of current medicinal chemistry research. Increasing number of immunocompromised patients due to chemotherapy, HIV infection and other multi resistant bacterial infections made the research in this field very important ${ }^{1,2}$.

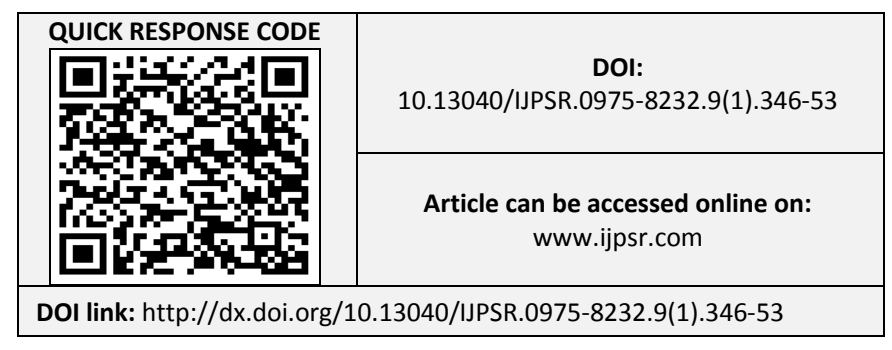

Kinase proteins are perceptible targets for anticancer drug design as they play main role in oncogenesis. US Food and Drug Administration has approved 11 kinase inhibitors and several researches are going on to develop specific small molecule inhibitors as host of different kinases which are affianced in cancer and other diseases ${ }^{3}$.

Schiff bases are considered as the 'privileged' ligands in the field of medicinal chemistry and drug research as they are easy to synthesis and have broad spectrum of biological activities like Antiinflammatory, Analgesic, Antimicrobial, Anticonvulsant, Anti-tubercular, Anticancer, Antioxidant, Anthelmintic and so forth. The nitrogen atom of the imine functional group of the Schiff base may be involved in the formation of a hydrogen bond with 
the active centres of cell constituents and interferes in normal cell processes. Succinctly, they are one of important class of compounds having therapeutic potential for the treatment of various diseases ${ }^{24}$. Schiff bases which can bind or cleave DNA are now in great consideration due to their importance in the development of anticancer and antimicrobial agents 1, 4, 5, 6 . Schiff bases are characterized by imine group $-\mathrm{N}=\mathrm{CH}$ - and they explicate the mechanism of transamination and racemization reactions in biological system ${ }^{7}$. Metal complexes of Schiff bases have been widely investigated due to their antitumor and herbicidal uses ${ }^{8}$.

Naphthalene Schiff bases with ortho-hydroxy substituent possess interesting structural characteristic like radiation induced or temperature induced reversible colour changes commonly known as photochromism and thermochromism respectively ${ }^{18}$. Similarly, inductive effects produced due to other substituents like methoxy or nitro functional groups play vital role on their biological activity. There are considerable researches devoted to the structural investigations of Schiff bases derived from naphthaldehyde, rather not as much of attention has been paid to investigate their biological activities. Hence our current research is intended to focus on the biological significance of Schiff bases derived from substituted naphthaldehydes. As a continuation of our interest, Schiff bases derived from naphthaldehyde and aniline were synthesised. The functional groups were deliberately planned to afford hydrogen bond donor and acceptor sites to ensure stronger interactions and biological activities. Anti bacterial activity, protein docking interactions and DNA cleavage activities of these Schiff bases were contemplated and their SAR was studied.

MATERIALS AND METHODS: All the reagents required for the synthesis of Schiff bases, DNA cleavage experiment as well as anti bacterial studies were brought from Aldrich Chemicals, Bangalore and were chemically pure. All the solvents were freshly distilled before use.

Experimental: General Procedure for the synthesis of Schiff bases: Aldehyde (1mmol) was dissolved by stirring in hot ethanol $(10 \mathrm{~mL})$. Aniline derivative (1mmol) was added slowly to the solution of aldehyde. This mixture was refluxed for 3 - 4 hrs. The resulting precipitates were filtered, washed with cold ethanol and dried over vacuum to give orange to yellow coloured products ${ }^{13}$.

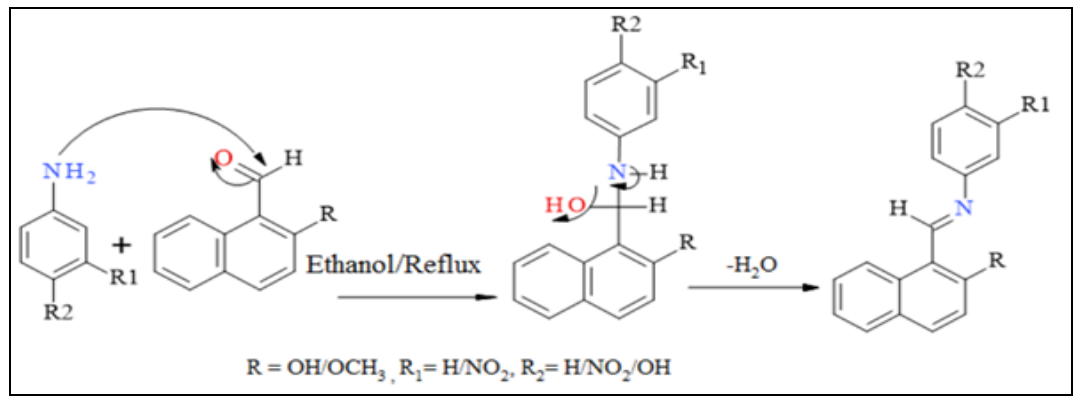

FIG. 1: SCHEME OF REACTION

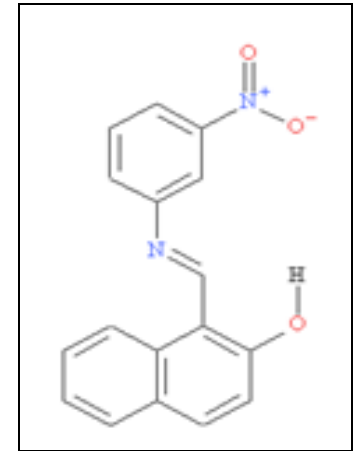

1-[(E)-(3-nitrophenyl) iminomethyl]naphthalene -2 -ol; L3(a)

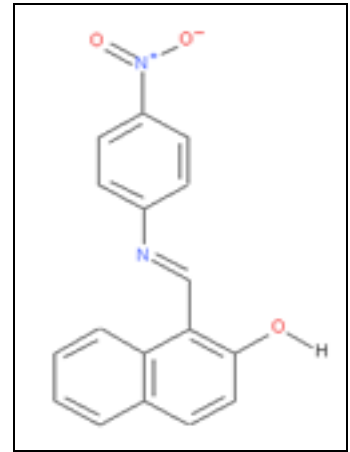

1-[(E)-(4-nitrophenyl) iminomethyl]naphthalene -2-ol; L3(b)

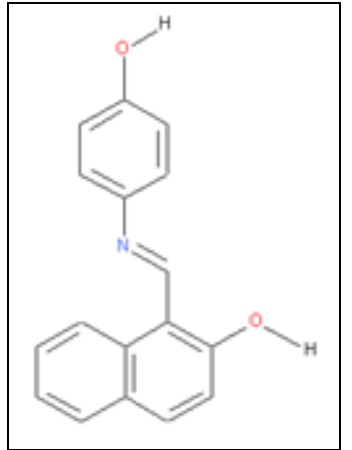

1-[(E)-(3-hydroxyphenyl) iminomethyl]naphthalene $-2-o l ;$ L3 (c) 


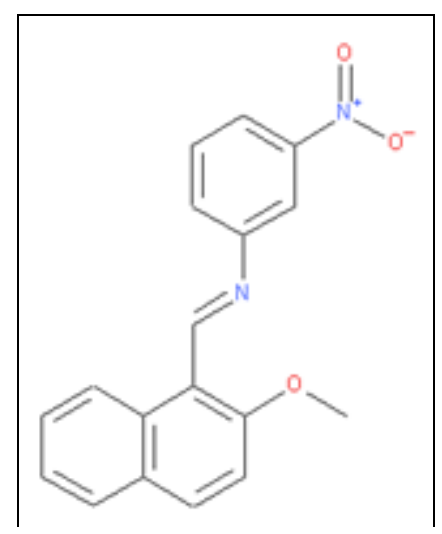

(E)-1-(2-methoxy-1-naphthyl)N-(3-nitrophenyl) methanimine; L3

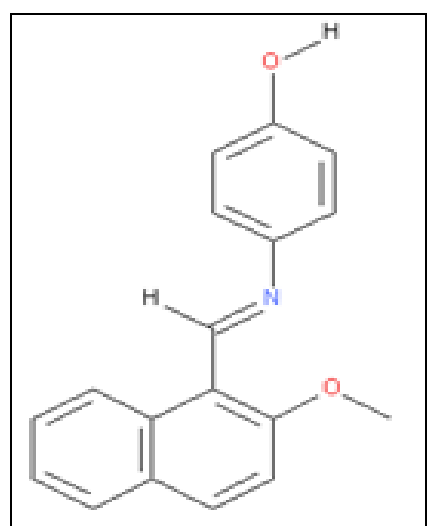

4-[(E)-(2-methoxy-1-naphthyl)(d) methyleneamino]phenol; L3 (e)

FIG. 2: SCHEMATIC DIAGRAM OF SCHIFF BASES L3 (a) TO L3 (e)

Docking Studies: Docking interactions of L3 (a) to L3 (e) with p55blk kinase protein were investigated by using the software PATCHDOCK and PYMOL. The ligand structures (2D) were sketched using CHEMSKETCH software and converted to 3D and further refined and optimized Using CHIMERA. Final .pdb file was generated for docking studies.

To allow flexibility in the ligand, it is necessary to assign the rotatable bonds; in this study all the rotamers were allowed. The pdb file of the protein (The three - dimensional solution structure of the SH2 domain from p55blk kinase) was downloaded from the database www.rcsb.org/pdb (pdb id is $1 \mathrm{BLJ})$. Docking of the ligands into receptor was carried out using BETA (1.3 version) set of programs.

Anti Bacterial Activities: Antibacterial activity of the synthesized compounds was tested against four bacterial strains using agar well diffusion method ${ }^{22}$. Muller Hilton Agar media was used to inoculate the bacteria culture. The test compounds were prepared in DMSO $(10 \mathrm{mg} / \mathrm{ml})$. These samples were loaded directly into 5 different wells in the media, kept in incubator for 17 hours at $30{ }^{\circ} \mathrm{C}$ and zone of inhibition was observed as diameter. All determinations were done in triplicates. Tetracycline and Gentamycin were used as the standards $(0.03 \mathrm{mg} / \mathrm{ml})$, where the zone of Inhibition was $1.1 \mathrm{~cm}$ and $0.8 \mathrm{~cm}$ respectively. The minimum inhibitory concentration (MIC) was obtained by serial broth-dilution method ${ }^{23}$ at different concentrations such as 20,40,50,60 and $80 \mu 1$. The results of MIC values of antimicrobial activity are given in Table 3.
DNA Cleavage Studies: The DNA cleavage experiment was conducted using Lambda DNA by gel electrophoresis in presence of $\mathrm{H}_{2} \mathrm{O}_{2}$ as oxidant. The reaction mixture was incubated at $35{ }^{\circ} \mathrm{C}$ for 2 hrs as follows: DNA $20 \mu \mathrm{M}$, Schiff base $40 \mu \mathrm{M}$, $\mathrm{H}_{2} \mathrm{O}_{2} \mu \mathrm{M}$ in Tris $\mathrm{HCl}$ buffer $(\mathrm{pH}=7.2)$. After incubation, the samples were electrophoresed for 2 $\mathrm{h}$ at $50 \mathrm{~V}$ on $1 \%$ agarose gel using Tris - $\mathrm{HCl}-$ EDTA buffer ( $\mathrm{pH}$ 8.8). The gel was then stained using $1 \mu \mathrm{g} / \mathrm{cm}$ Ethidium bromide (EB) and photographed under ultraviolet light at $360 \mathrm{~nm}$. All the experiments were performed at room temperature.

\section{RESULTS AND DISCUSSION:}

Docking Studies: Changes within the structure of a ligand can alter the strength and quality of its interactions with a receptor in any particular series of compounds. The first Kinase inhibitor reached in clinic was Gefitinib and it contains quinazoline fused ring system as well as substituted anilines in their structure. Bosutinib and Lapatinib are also kinase protein inhibitors which restrain aniline ring in their composition ${ }^{9}$. Similarly, a large numbers of naphthalene derivatives are also proved as biologically active ${ }^{15-17}$. Research works published by Kim MH et al., on a series of molecules containing naphthalene rings are proved as potent and selective JNK3 inhibitor in cell, dramatically reducing phosphorylation of $\mathrm{C}$ - Jun ${ }^{14}$. Considering these factors, we have introduced ortho substituted naphthyl ring as well as substituted aniline in the structure of each Schiff bases to analyse the importance of these groups in attaining suitable 'pose' for inhibiting blk Kinase. Functional groups in these moieties are designed in such a way that 
molecules should contain an activating group $(-\mathrm{OH}$, $\left.-\mathrm{OCH}_{3}\right)$ and a deactivating group $\left(-\mathrm{NO}_{2}\right)$ to evaluate the consequences of these groups in different positions. In L3 (b), as the nitro group is at the para position of amine precursor; it is expected to have more control on the basicity of the imine nitrogen ${ }^{13}$. Where as in L3 (a) and L3 (d), this nitro group is at the meta position which have comparatively lesser effect on the imine nitrogen. Similarly, ortho hydroxyl group on the naphthalene ring is expected to act as hydrogen bond donor, and methoxy group as hydrogen bond acceptor ${ }^{21}$. The synthesised compounds L3 (a) to L3 (e) were tested for their docking, antibacterial as well as DNA cleavage activities. Out of five Schiff bases, L3 (a) and L3 (d) exhibited docking through two types of interactions; hydrogen bonding and statistical potential or knowledge based interactions. These rings are more prone to have electrostatic interactions with the receptor proteins ${ }^{20}$. The nonhydrogen bond interaction called knowledge-based (also known as statistical potentials) is based on statistical observations of intermolecular close contacts which are used to derive "potentials of mean force" 10, 11. This method is based on the assumptions that close intermolecular interactions between certain types of atoms or functional groups that occur more frequently than one would expect by a random distribution are likely to be energetically favourable and therefore contribute favourably to binding affinity. Knowledge - based interactions have become accepted choices for fast scoring putative protein - ligand complexes according to their binding affinities ${ }^{10}$.

Although an ortho hydroxyl group in the molecular structure of L3 (a) was strategically placed to afford a hydrogen bond donor site, there were no fascinating hydrogen bond formation with the receptor protein. A glimpse on the structures of such Schiff bases with ortho hydroxyl groups show that they can exist in two different resonance stabilised tautomeric structures; enol-imine and keto-amine forms which explain the inability of these groups to undergo hydrogen bond with the kinase protein ${ }^{18,19}$. In L3 (d), the imine nitrogen is not providing a hydrogen bond acceptor site due to an intramolecular ' $\mathrm{C}-\mathrm{H}$... $\mathrm{N}$ ' interaction as shown in Fig. $4^{12}$. X-ray crystallographic data of L3 (d) shows that it does not possess a planar structure as the naphthalene and aniline rings are twisted each other through C-N bond (Fig. 3) ${ }^{12}$. It is interesting to scrutinize an attractive docking aptitude exhibited by this non planar molecule.

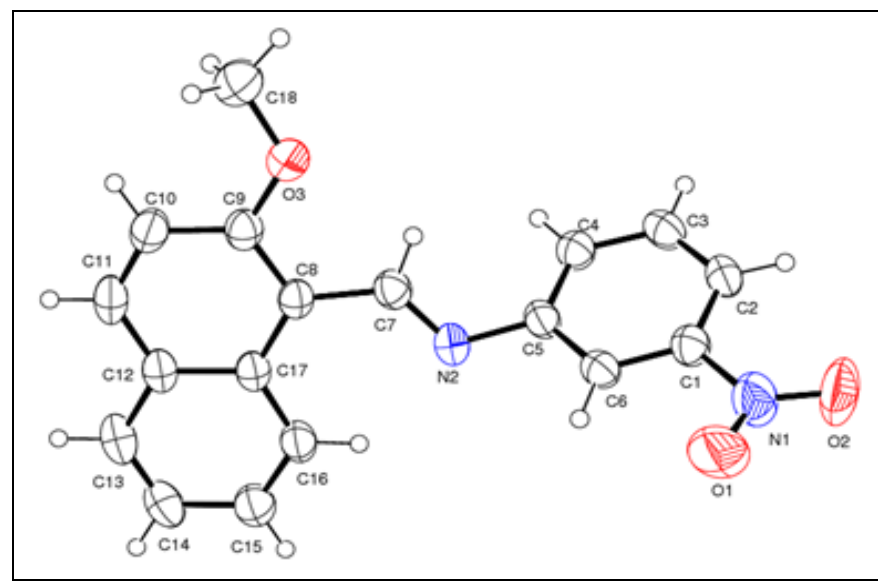

FIG. 3: X-RAY CRYSTALLOGRAPHY STRUCTURE OF NON PLANAR MOLECULE L3 (d) ${ }^{12}$

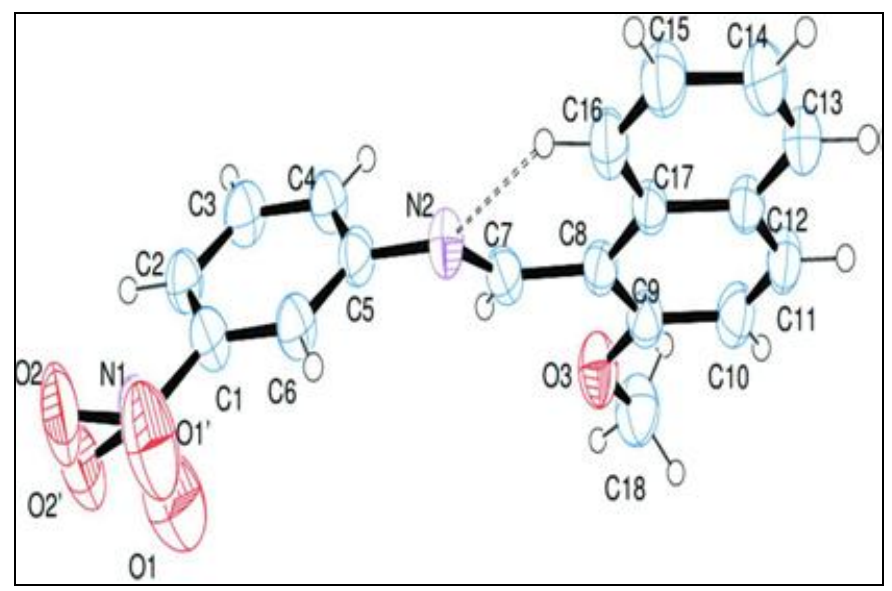

FIG. 4: X-RAY CRYSTALLOGRAPHY STRUCTURE OF L3 (d) TO EXHIBIT THE 'C-H...N' INTERACTION ${ }^{12}$

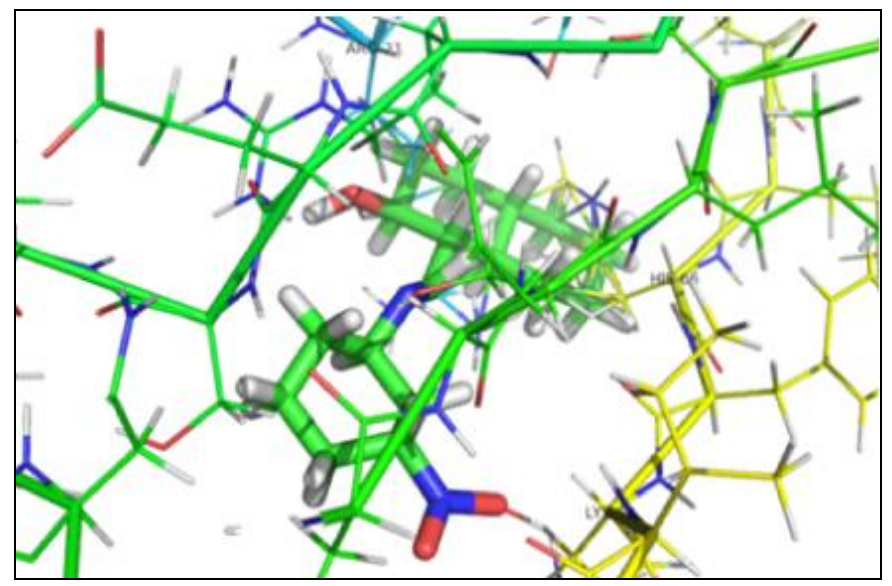

FIG. 5: INTERACTIONS OF L3 (a) WITH p55blk KINASE PROTEIN

Compound L3 (a) exhibits 24 Knowledge - based interactions with three different amino acid residues ARG21, HIS66 and LYS68 from p55blk kinase. The total docking score calculated was - 
$4.334 \mathrm{kcal} / \mathrm{mol}$ (Table 1). Naphthalene ring was found to be in close contact with the amino acids ARG21 and HIS66. Similarly LYS68 was in the vicinity of the nitro functional group of L3 (a) to provide the interactions based on statistical potential.

TABLE 1: DOCKING INTERACTIONS OF L3 (a) WITH DIFFERENT AMINO ACID RESIDUES

\begin{tabular}{cccc}
\hline Total score & Interacting amino acid & Interactions & Bonding \\
\hline$-4.334 \mathrm{kcal} / \mathrm{mol}$ & ARG21 & 12 & Knowledge-based \\
& HIS66 & 11 & Knowledge-based \\
& LYS68 & 1 & Knowledge-based \\
\hline
\end{tabular}

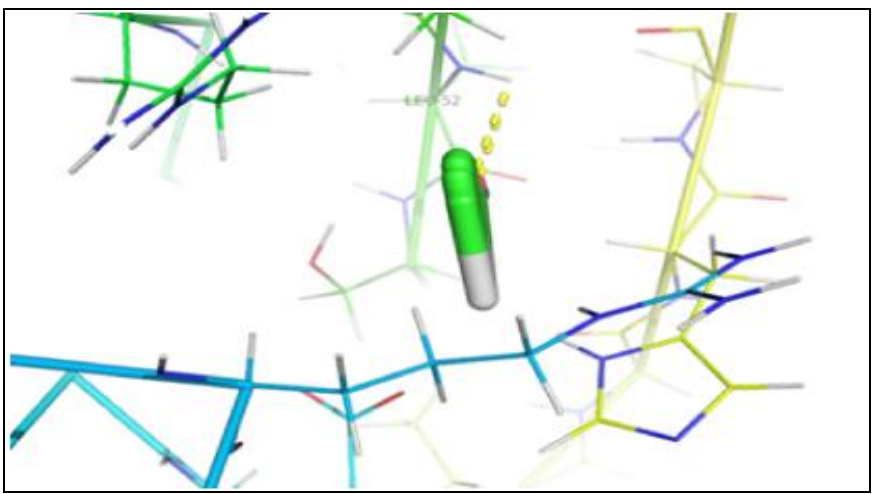

FIG. 6: INTERACTIONS OF L3 (d) WITH p55blk KINASE PROTEIN

The Compound L3 (d) shows 2 hydrogen bonding interactions with LEU52 in the receptor protein, where $\mathrm{OH}$ group from the amino acid residue interacts with two different $\mathrm{H}$ atoms of naphthalene rings. Docking score is $-4.334 \mathrm{kcal} / \mathrm{mol}$ (Table 2).

TABLE 2: DOCKING INTERACTIONS OF L3 (d) WITH AMINO ACID RESIDUES

\begin{tabular}{cccc}
\hline Score & Interacting amino acid & Interactions & Bonding \\
\hline$-4.334 \mathrm{kcal} / \mathrm{mol}$ & LEU52 & 2 & $\mathrm{H}-\mathrm{OH}$ \\
\hline
\end{tabular}

Antibacterial Studies: Antibacterial activity of the Schiff bases L3 (a) to L3 (e) were investigated with E. coli, Pseudomonas aerogenase, Staphylococcus aureus and Bacillus Cereus.

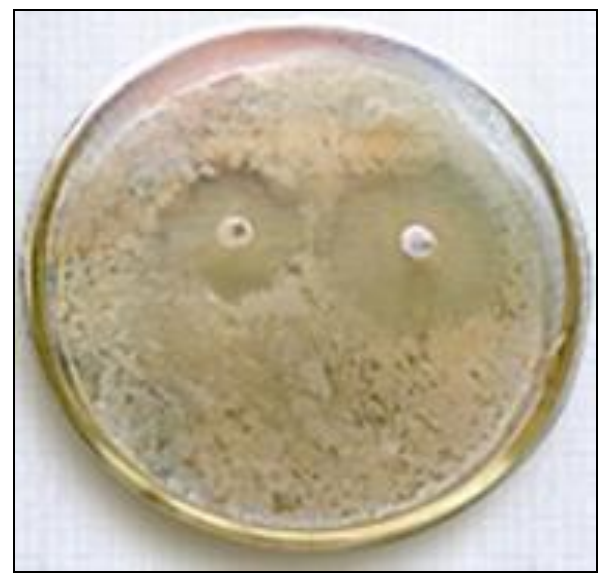

FIG. 7: TETRACYCLINE ZONE OF INHIBITION IS $1.1 \mathrm{~cm}$ AND GENTAMYCIN IS $0.8 \mathrm{~cm}$

The investigation of antibacterial screening reveals that the compounds L3 (c), L3 (d) and L3 (e) has varying degree of activity against tested microorganisms.
The compound L3 (c) which carries two $\mathrm{OH}$ functional groups (Fig. 2) was observed as the most successful among all the Schiff bases and was active against all the tested bacterial strains (Table 3 and 4). This result supports the findings done by S. Hisaindee et al., whose research demonstrate the broad-spectrum inhibitory activity of Schiff base compounds containing hydroxyl group against microorganisms ${ }^{13}$. Hence it is worth to compare the observation made by Mr. Soleiman Hisaindee and co workers; that a structurally similar Schiff base derived from 2-hydroxy naphthaldehyde (compound number 10) was inactive against $E$. coli ${ }^{13}$. But we observed an improved activity by adding a hydroxyl group at the para position of aniline precursor. Similarly, it is interesting to note that the compounds L3 (d) and L3 (e) which are derived from 2-methoxy naphthaldehyde are found to be active against gram positive bacteria. Compounds L3 (a) and L3 (b) are inactive against all the tested bacterial strains and they carry an electron withdrawing nitro group at the aniline site in common. 


\section{TABLE 3: ANTIBACTERIAL ACTIVITY SCHIFF BASE LIGANDS}

\begin{tabular}{cccc}
\hline Compound & Bacteria & Concentration & Zone of inhibition (cm) \\
\hline L3(c) & Bacillus Cereus & $80 \mu 1$ sample & 1.2 \\
L3(c) & E. coli & $20 \mu 1$ sample & 1.2 \\
L3(c) & E. coli & $40 \mu 1$ sample & 1.2 \\
L3(c) & E. coli & $60 \mu 1$ sample & 1.3 \\
L3(c) & E. coli & $80 \mu 1$ sample & 1.0 \\
L3(c) & E. coli & $50 \mu 1$ sample (DMSO) & 3.5 \\
L3(c) & Pseudomonas aeruginosa $(\mathrm{G}-)$ & $20 \mu 1$ sample & 1.2 \\
L3(c) & Pseudomonas & $40 \mu 1$ sample & 1.2 \\
L3(c) & Pseudomonas & $60 \mu 1$ sample & 1.3 \\
L3(c) & Pseudomonas & $80 \mu 1$ sample & 1.0 \\
L3(c) & Pseudomonas & $50 \mu 1$ sample (DMSO) & 3.5 \\
L3(d) & Bacillus cereus & $20 \mu 1$ sample & 1.4 \\
L3(d) & Bacillus cereus & $40 \mu 1$ sample & 1.2 \\
L3(d) & Bacillus cereus & $60 \mu 1$ sample & 1.0 \\
L3(d) & Bacillus cereus & $80 \mu 1$ sample & 1.0 \\
L3(d) & Bacillus cereus & $50 \mu 1$ sample (DMSO) & 0.0 \\
L3(e) & Staphylococcus aureus & $20 \mu 1$ sample & 0.0 \\
L3(e) & Staphylococcus & $40 \mu 1$ sample & 0.0 \\
L3(e) & Staphylococcus & $60 \mu 1$ sample & 0.4 \\
L3(e) & Staphylococcus & $80 \mu 1$ sample & 0.6 \\
L3(e) & Staphylococcus & $50 \mu 1$ sample (DMSO) & 0.0 \\
\hline
\end{tabular}

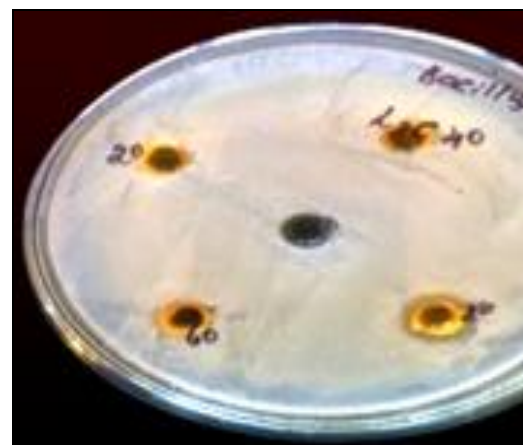

BACILLUS CEREUS

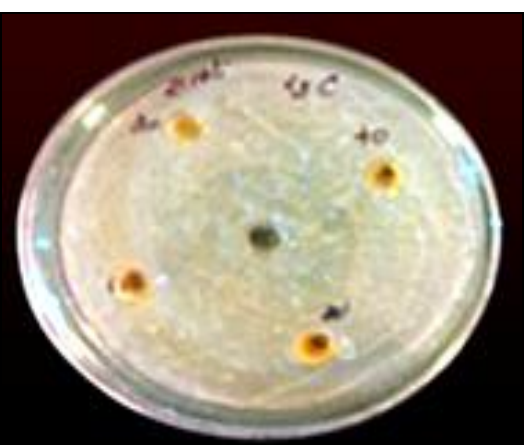

E. COLI

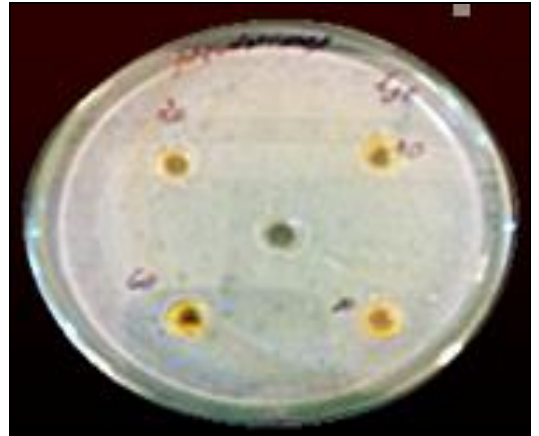

PSEUDOMONAS

FIG. 8: ANTIBACTERIAL ACTIVITIES OF L3 (c)

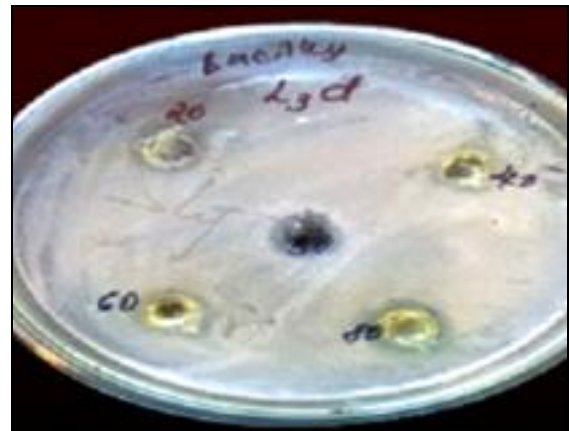

FIG. 9: ANTIBACTERIAL ACTIVITIES OF L3 (D): BACILLUS CEREUS

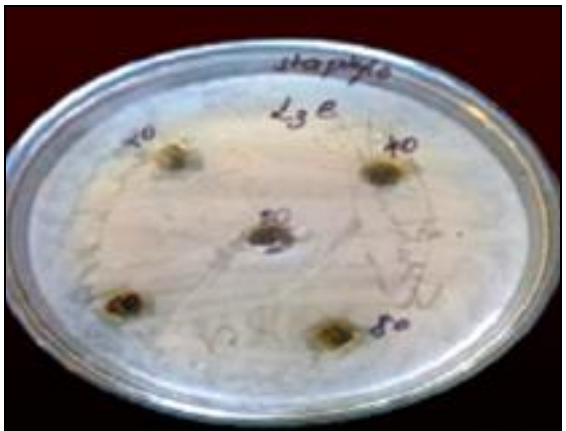

FIG. 10: ANTIBACTERIAL ACTIVITIES OF L3 (E): STAPHYLOCOCCUS AUREUS

TABLE 4: SCHIFF BASE LIGANDS THOSE WHICH DOES NOT SHOW ANTIBACTERIAL ACTIVITY

\begin{tabular}{cc}
\hline Compounds & Bacteria \\
\hline L3(a) & Bacillus cereus \\
L3 a & \\
L3(a) & Staphylococcus aureus \\
L3 a & E. coli \\
L3(a) & Pseudomonas aeruginosa \\
L3(a)
\end{tabular}




\begin{tabular}{cc}
\hline L3(b) & Bacillus Cereus \\
L3(b) & Staphylococcus aureus \\
L3(b) & E. coli \\
L3(b) & Pseudomonas aeruginosa \\
L3(c) & Staphylococcus aureus \\
L3(d) & Staphylococcus aureus \\
L3(d) & E. coli \\
L3 (d) & Pseudomonas aeruginosa \\
L3(e) & Bacillus xereus \\
L3(e) & E. coli \\
L3(e) & Pseudomonas aeruginosa \\
\hline
\end{tabular}

\section{DNA Cleavage Studies:}

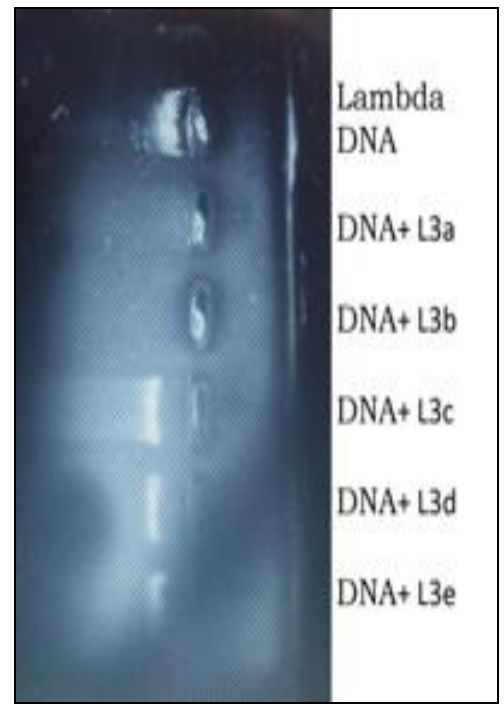

FIG. 11: GEL ELECTROPHORESIS DIAGRAM OF THE SCHIFF BASE COMPOUNDS

Lane 1: Control DNA; Lane 2: L3 (a) + Lambda DNA+ $\mathrm{H}_{2} \mathrm{O}_{2}$; Lane 3: L3 (b) + Lambda DNA+ $\mathrm{H}_{2} \mathrm{O}_{2}$; Lane 4: L3 (c) + Lambda DNA $+\mathrm{H}_{2} \mathrm{O}_{2}$; Lane 5: L3 (d) + Lambda DNA $+\mathrm{H}_{2} \mathrm{O}_{2}$; Lane 6: $\mathrm{L} 3$ (e) + Lambda DNA $+\mathrm{H}_{2} \mathrm{O}_{2}$

DNA cleavage activity was monitored by gel electrophoresis, using a control sample (lane 1). Result tells that cleavage obtained for L3 (d) (lane 5), and L3 (e) (lane 6) are insignificant. But a considerable cleavage was observed for the Schiff base L3 (a) (lane 2), L3 (b), and L3 (c). The study reveals that L3 (a), L3 (b) and L3 (c) are able to convert super coiled DNA in to open circular DNA more efficiently than other Schiff base ligands in this series. Presence of smear on the electrophoresis gel is the evidence for the oxidative cleavage.

CONCLUSION: Antibacterial activity, protein docking and DNA cleavage activity of structurally related Schiff bases were investigated. Schiff base Ligand L3 (a) which posses an electron donating hydroxyl group as well as an electron withdrawing nitro group was found to be an excellent docking agent for p55blk kinase protein with 24 docking interactions; while the Schiff base ligand L3 (c) which possess two electron donating hydroxyl groups was observed as superior antibacterial agent against E. coli and Pseudomonas aeruginosa with an inhibition zone of $3.5 \mathrm{~cm}$. Thus the present work reports the role of hydrogen bond donor and acceptor groups, steric hindrance and effects of substituents in the core structure of the molecule in developing a better, target specific potential drug molecule.

ACKNOWLEDGEMENT: The authors are thankful to The Government Science College Bangalore, India and The Oxford College of Science Bangalore, India for providing the necessary facilities to carry out the present work; we also thank SSMRV Degree College Bangalore, India and $\mathrm{R} \& \mathrm{D}$ centre, Bharathiar University Coimbatore, India for the constant encouragement.

DISCLOSURE OF INTEREST: The authors declare that they have no conflict of interest.

\section{REFERENCES:}

1. Wright PM, Seiple IB and Angew AMG: The Evolving Role of Chemical Synthesis in Antibacterial Drug Chem. Int. Ed. 2014; 53: 2 - 32.

2. Huq CAMA and Fouzia S: Synthesis of novel Schiff bases and evaluation of their anti-microbial activities. Indian $\mathrm{J}$. Chem. 2015; 54: 551-555.

3. Jianming Z, Priscilla YL and Nathanael GS: Targeting cancer with small molecule kinase inhibitors. Nat. Rev. Cancer 2009; 9: 28-39.

4. Lei X, Yu-Fen X, Li-Rong H, Xiao X, Hua-Yong L, TangJingjun L, Wei-Dong P and Heng L: Benzaldehyde Schiff bases regulation to the metabolism, hemolysis, and virulence genes expression in vitro and their structuremicrobicidal activity relationship. Eur. J. Med. Chem. 2015; 97: 83-93.

5. Abu-Dief AM and Mohamed IMA: A review on versatile applications of transition metal complexes incorporating Schiff bases. Ben-Seuf Univ. J. Appl. Sci. 2015; 4: 119 -133

6. Abd-Elzaher MM, Labib AA, Mousa HA, Moustafa SA, Ali MM and El-Rashedy AA: Synthesis, anticancer 
activity and molecular docking study of Schiff base complexes containing thiazole moiety. Beni-Seuf Univ. J. Appl. Sci. 2016; 5: 85-96.

7. Jie $\mathrm{H}, \mathrm{Yu} \mathrm{Z}$ and $\mathrm{Li} \mathrm{Z}$ : Synthesis and in vitro anticancer activities of novel aryl-naphthalene lignans. Med. Chem. Res. 2012; 21: 3994-4001.

8. Golcu A, Tumer M, Demirelli H and Wheatley R: Cd (II) and $\mathrm{Cu}$ (II) complexes of polydentate Schiff base ligands: synthesis, characterization, properties and biological activity. Inorg. Chim. Acta. 2005; 358: 1785-1797.

9. Graham PL and John S: An introduction to medicinal chemistry: Anti cancer Drugs, $4^{\text {th }}$ Edition. Oxford University Press, New York 2009; 1: 553- 558.

10. Muegge I: PMF scoring revisited. J. Med. Chem. 2006; 49: $5895-5902$.

11. Jagadeesh NM, Mahadevan KM and Bagachi P: Synthesis, Molecular docking and Fluorescent properties of Novel (E)-3-(9-Ethyl-9H-Carbazol-3yl)-1-Phenylprop-2-en-1ones. Int. J. Pharm. Pharm. Sci. 2014; 6: 317-325.

12. Devika BR, Girija CR, Shalini S and Ramakrishna R: Crystal structure of (E)-N- [(2-methoxynaphthalen-1-yl) methylidene]-3-nitroaniline. Acta Crystallogr. Sect. E 2015; 71: 0941-0942.

13. Hisaindee S, Al-Kaabi L, Ajeb S, Torky Y, Iratni R, Saleh $\mathrm{N}$ and AbuQamar SF: Anti pathogenic effect of Structurally Related Schiff base Derivatives; Structureactivity relationship. Arabian J. Chem. 2013; 8: 828-836.

14. Mi-hyun K, Junghun L, Kyungjin J, Minjung K, Yun-Jin P, Kwon HAYH and Jung-Mi H: Synthesis and biological evaluation of 1-heteroaryl- 2-aryl- $1 \mathrm{H}$ - benzimidazole derivatives as c-Jun N-terminal kinase inhibitors with neuroprotective effects. Bioorg. Med. Chem. 2013; 21: 2271-2285.

15. Wen Yang, Yang Hu, Yu-Shun Yang, Fei Zha, Yan-Bin Zhang, Xiao-Liang Wang, Jian-Feng Tang, Wei-Qing Zhong, Hai-Liang Zhu: Design, modification and 3D QSAR studies of novel naphthalin-containing pyrazoline derivatives with/without thiourea skeleton as anticancer agents. Bioorg. Med. Chem. 2013; 21: 1050-1063.
16. Altıntop MD, Atlı O, Ilgın S, Demirel R, Özdemir A and Kaplancikl ZA: Synthesis and biological evaluation of new naphthalene substituted thiosemicarb azone derivatives as potent antifungal and anticancer agents. Eur. J. Med. Chem. 2015. DOI: 10.1016/j.ejmech.2015.11.041.

17. Mingwei S, Jinhuan O, Wenjun L and Chunhua L: Quinoline and naphthalene derivatives from Saccharopolyspora sp. YIM M13568. J. Antibiot. 2017; 70: 320-322. doi:10.1038/ja.2016.142.

18. Shao PZ, Yuan C, Jun S, Yu TY, and Chuan JY: Synthesis, Characterization, Thermochromism and Photochromism of Aromatic Aldehyde Hydrazone Derivatives. J Chem 2016; 1-8.

19. Tahir SA, Liudmil A and Walter MFF: Phenol-Quinone Tautomerism in (Arylazo)naphthols and the Analogous Schiff Bases: Benchmark Calculations. J. Phys. Chem. A 2014; 118: 778-789, DOI: 10.1021/jp411502u.

20. Stefania S, Marco M, Ryan T, Maria R, Giorgio C, Mario AP, Flavio M, Giuseppe Z, Roberto B and Lorenzo AP: Structural features underlying the selectivity of the kinase inhibitors NBC and DNBC: role of a nitro group that discriminates between CK2 and DYRK1A. Cell. Mol. Life Sci. 2012; 69: 449-460.

21. Marcin P and Sławomir JG: Methoxy group as an acceptor of proton in hydrogen bonds. J. Mol. Struct. 2002; 642: 13 97-104,

22. Mounyr B, Moulay S and Saad K: Methods for in vitro evaluating antimicrobial activity: A review. j.jpha. 2016; 6: 71-79.

23. Tan JBL and Lim YY: Critical analysis of current methods for assessing the in vitro antioxidant and antibacterial activity of plant extracts. Food Chem 2015; 172: 814-822. https://doi.org/10.1016/j.foodchem.2014.09.141.

24. Suresh S, Girija CR, Sathish CD and Venkatesha TV: Schiff Base N-(5-Chlorosalicylidene) Aniline, a Novel Antifungal Agent: Insights from Crystallographic Analysis, Semi Empirical and Molinspirations Calculations. Chem Sci J 2016; 7: 122. doi:10.4172/21503494.1000122 .

\section{How to cite this article:}

Bhai RD, Girija CR and Reddy RK: Schiff bases derived from 2-hydroxy and 2- methoxy naphthaldehyde: exploration of in silico docking, DNA cleavage, antibacterial activities and SAR. Int J Pharm Sci \& Res 2018; 9(1): 346-53. doi: 10.13040/IJPSR.0975-8232.9(1).346-53.

All @ 2013 are reserved by International Journal of Pharmaceutical Sciences and Research. This Journal licensed under a Creative Commons Attribution-NonCommercial-ShareAlike 3.0 Unported License.

This article can be downloaded to ANDROID OS based mobile. Scan QR Code using Code/Bar Scanner from your mobile. (Scanners are available on Google Playstore) 